\title{
Microstructure and Mechanical Properties of the Butt Joint in High Density Polyethylene Pipe
}

\author{
Pashupati Pokharel, Yoonsang Kim, and Sunwoong Choi \\ Department of Polymer Science and Engineering, Hannam University, Daejeon 305-811, Republic of Korea \\ Correspondence should be addressed to Pashupati Pokharel; ppokharel@gm.hannam.ac.kr and Sunwoong Choi; swchoi@hnu.kr
}

Received 19 May 2016; Revised 5 August 2016; Accepted 1 September 2016

Academic Editor: Volker Schoeppner

Copyright ( 2016 Pashupati Pokharel et al. This is an open access article distributed under the Creative Commons Attribution License, which permits unrestricted use, distribution, and reproduction in any medium, provided the original work is properly cited.

\begin{abstract}
The microstructure and mechanical properties of the butt joint in high density polyethylene (HDPE) pipes were evaluated by preparing the joints with increasing the cooling time from $10 \mathrm{~s}$ to $70 \mathrm{~s}$ before pressure created for fusion of the pipes. Here, cold fusion flaws in HDPE butt joint were created with increasing the cooling time around $70 \mathrm{~s}$ caused by the close molecular contact followed by insufficient interdiffusion of chain segments back and forth across the wetted interface. The tensile failure mechanism of the welded pipes at different fusion time was projected based on the tensile test of dog-bone shaped, fully notched bar type as well as round U-notched specimens. The mechanical properties of the joints at different fusion time were correlated with the corresponding fracture surface morphology. The weld seam as well as tensile fracture surfaces were etched using strong oxidizing agents. The crystallinity of surface etched weld zone by potassium permanganate based etchant was found higher than unetched sample due to the higher susceptibility of amorphous phase of polyethylene with oxidizing agent. The U-notched tensile test of butt welded HDPE pipe and surface etching of the weldments provided clear delineation about the joint quality.
\end{abstract}

\section{Introduction}

Polyethylene (PE) pipes have been used for carrying water and gas throughout the world from many decades. PE pipe can solve a broad range of piping problems such as corrosion and abrasion in industrial, municipal, mining, landfill, marine, and agricultural applications cost effectively. High welding capability of $\mathrm{PE}$ has been very useful to join PE materials through various fusion joining techniques [1]. Butt fusion welding, electrofusion welding, and extrusion welding are the most widely used joining methods for high density polyethylene (HDPE) pipes [2-9]. Because of a low cost and relatively simple procedure, hot plate butt fusion welding has prolonged enormous popularity for welding of $\mathrm{PE}$ pipes in the plastic pipe industry. In such welding process, melting point is an important parameter and should be considered during joining the different grades of PE satisfactorily [8]. During welding of PE pipes, the mobile macromolecules change their location and the joint parts cool down under pressure for a sufficient period of time. Thus, the macromolecules reach a state of lower molecular mobility due to cooling and are less capable of changing their positions $[9,10]$.

The developed interfaces after welding of plastic pipes are usually weaker than the parent pipes. The strength and the quality of a joint depend on not only the geometry of the weld bead through a slight or a stronger notch effect but also the microstructure of welded area $[6,11]$. In that line, various factors such as welding parameters and thermal history of polymer have been recognized on the strength and the quality of a weld seam $[12,13]$. Different mechanical testing methods are used to determine the weld seam force transmission. Conventional short-term tests of weld seam like short-term tensile test and bend test have not shown strongly differentiating statements about the quality of a weld seam [11]. The standard and nonstandard conditions of weld can be distinguished in terms of morphological behavior $[6,11,14]$. Furthermore, the microstructures of weld zone and heat affected zone determine the ultimate quality and mechanical properties of the joint. According to Barber and Atkinson [14], the heating and cooling process at the weld 


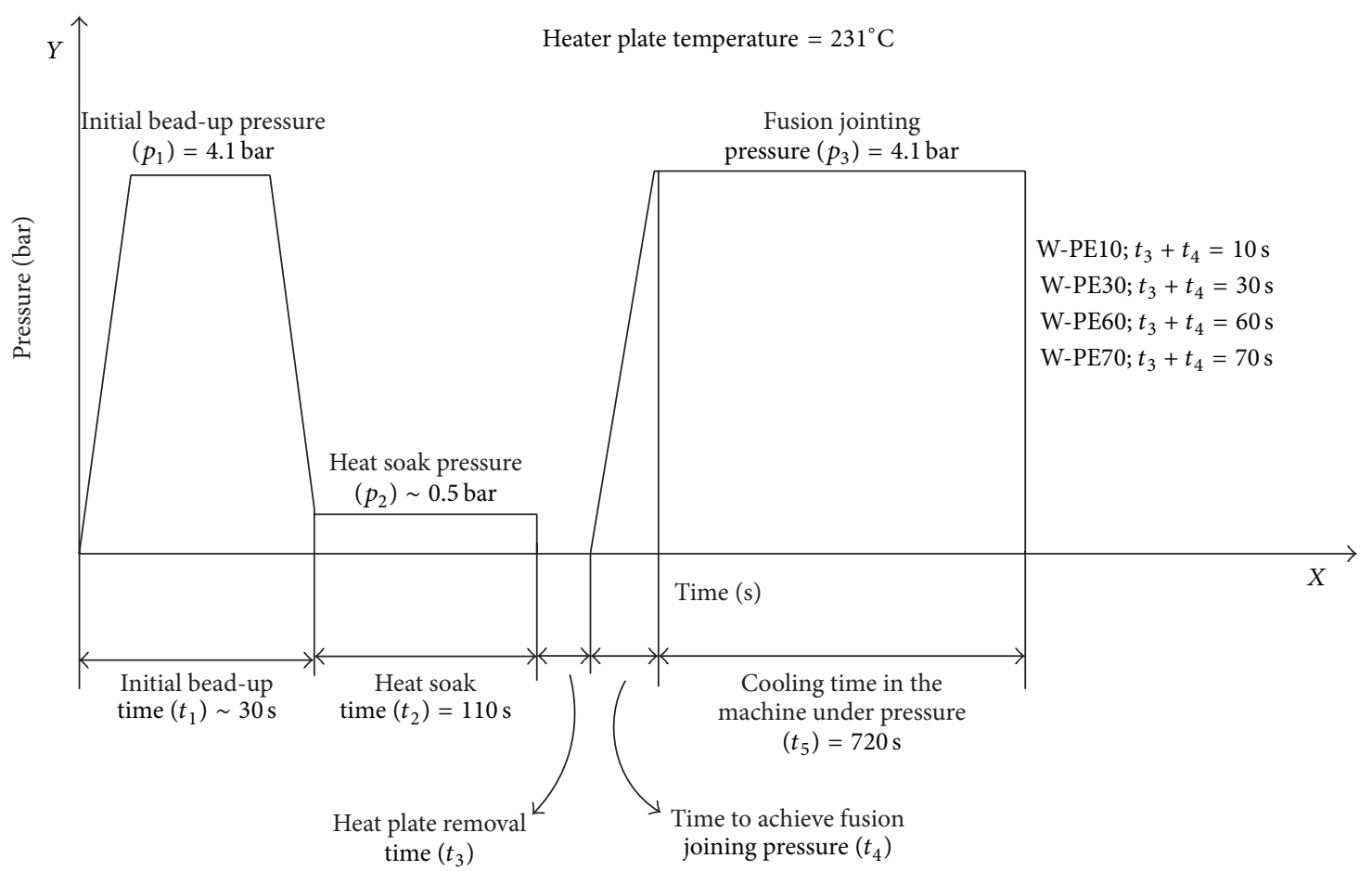

FIGURE 1: Schematic showing the butt fusion welding profile of HDPE pipes with the variation of fusion time.

creates microstructure that differs from the base material. According to their study, the weld microstructure has 5 distinct regions, namely, skin remnant, spherulitic slightly elongated, columnar, boundary nucleation, and spherulitic. In addition, Schmachtenberg and $\mathrm{Tu}$ [6] reported well distinguishable six regions as moving from the weld centerline to the base material of hot plate welded polypropylene. In that study, they noticed the linear, coarse, fine, oriented, and stretched spherulitic morphology at the weld and heat affected zone. To understand the developed interfaces after butt fusion of HDPE pipes, it is essential to distinguish the polymer chains segregation at the weld zone. Evaluation of the morphologies and mechanical properties of welded pipe with the variation of cooling time before pressure created for fusion may provide the information about the quality of joint.

To distinguish a defect caused by cold fusion, it is very important to correlate the mechanical properties of joint at different welding conditions with the respective weldment surfaces after etching. Etching the weldment using a mixture of strong acid and oxidizing agent often reveals residual stresses by preferential attack of material in amorphous regions and/or of lower molecular weight (MW) crystalline material $[11,15]$. Even though there are few earlier reports about the morphological feature of weld zone and heat affected zone $[6,11,14,16]$, enough studies are not found in an open literature about the cold fusion flaws based on microstructure and mechanical properties of joints. External conditions, such as temperature, wind, and moisture, and contaminants like pollen grains during welding at outdoor situation also negatively impact the quality of the pipe fusion joint. An incomplete fusion of the two pipe halves produces a cold fusion joint, possibly only a molecular level. Cold fusion is a specific type of defect that has been the most elusive to detect in the HDPE butt or thermal fusion joints. The failure at a cold fusion joint after some service time may be due to thermal ratcheting or fatigue or creep failure. It is essential to reliably identify cold fusion flaws in the joints to ensure sound fusion properties of the joint. In this study, cold fusion flaws were developed at the butt joint with increasing the cooling time before pressure created for fusion of the pipes and that was compared with butt joint at standard condition. The microstructures of the butt joint at different welding conditions were evaluated after etching the weldment with strong oxidizing agents.

\section{Materials and Methods}

2.1. Butt Fusion Welding of HDPE Pipes and Sampling of Weldments. HDPE pipes (SDR 9, D = $110 \mathrm{~mm}$ ) were welded at $231^{\circ} \mathrm{C}$ under 4.1 -bar pressure using automatic butt fusion machine (NUC-II WMS, world map system, Korea) [15]. The details of the welding profile, that is, a plot of pressure versus time during the butt fusion welding of HDPE pipes, are shown in Figure 1. During butt fusion welding, the sum of the heater plate removal time $\left(t_{3}\right)$ and the time to achieve fusion joining pressure $\left(t_{4}\right)$ was varied from 10 to $70 \mathrm{~s}$ keeping other conditions constant. The material codes were given as $\mathrm{W}$ PE10, W-PE30, W-PE60, and W-PE70 for butt joints having fusion times $10 \mathrm{~s}, 20 \mathrm{~s}, 30 \mathrm{~s}, 60 \mathrm{~s}$, and $70 \mathrm{~s}$, respectively. The pipe was cut longitudinally placing the welded zone at the middle of sample for the preparation of dog-bone shaped as well as bar type specimens. Tensile tests of the butt weld 
samples at different fusion time were performed at $23 \pm 2^{\circ} \mathrm{C}$ on a universal testing machine (Shimadzu Corporation, Japan). Tensile test of dog-bone shaped specimens was performed without notching at a cross head speed of $50 \mathrm{~mm} / \mathrm{min}$ according to the ASTM D638-10, type I specification. Specimens from parent materials without welding were also prepared similarly and tested at the same condition for the comparison. The average values of the three samples were used for plotting the yield strength and elongation at break. For bar type specimens, sample size (thickness $\times$ width) was fixed 10 $\times 10 \mathrm{~mm}^{2}$ and full notch was made $35 \%$ of the thickness at the weld zone of W-PE10, W-PE30, and W-PE60 using notching machine (AG-5000G Shimadzu). But, during the development of full notch at the joint of the rectangular bar of W-PE70, the sample was broken into two pieces from joint. So, bar type W-PE70 samples without notch were used for tensile test. All the samples were tested with a cross head speed $1 \mathrm{~mm} / \mathrm{min}$ at room temperature. We also performed the tensile test of round notched specimens of butt welded HDPE pipes. For this purpose, the outer bead of the pipe was removed and a round notch with a depth of $1.6 \mathrm{~mm}$ was made on the joint of the pipe using cutter having U-shaped blades with the notching speed of about $10 \mathrm{~mm} / \mathrm{min}$. The Unotched sample size (thickness $\times$ breath) was fixed $10.6 \times$ $20 \mathrm{~mm}^{2}$ without considering inner bead of butt joint. The fracture surface morphology of butt fusion joint before and after etching by potassium permanganate based etchant was correlated with the mechanical properties of the samples at different fusion time.

2.2. Surface Etching of the Weldment. The surface of weld seam (thickness $12 \mathrm{~mm}$ ) was obtained after milling of butt welded pipe and made smooth using microtome (ESM-150S, ERMA Inc., Japan) having a tungsten carbide tipped steel blade with a blade angle of $10^{\circ}$ on the weldment sample at room temperature. Etching of the weldment was performed using two different types of oxidizing agents. First etchant was prepared by dissolving $5 \mathrm{~g}$ potassium permanganate in $100 \mathrm{~mL}$ of sulphuric acid and that was used for etching of weldments at $25^{\circ} \mathrm{C}$ for $24 \mathrm{~h}$. Similarly, second etchant was prepared by dissolving $5 \mathrm{~g}$ chromium trioxide into the mixture of $100 \mathrm{~mL}$ sulfuric acid, $20 \mathrm{~mL}$ orthophosphoric acid, and $20 \mathrm{~mL}$ water. Then, the weldments were added in the beaker containing above etchant for etching at $75^{\circ} \mathrm{C}$ for $48 \mathrm{~h}$. In both chemical etching techniques, the etchant was removed from weldment by ultrasonic cleaning in water (10 $\mathrm{min})$ and next acetone $(10 \mathrm{~min})$. The weldments were dried in a conventional oven at $70^{\circ} \mathrm{C}$ for $24 \mathrm{~h}$.

2.3. Characterization. Fourier transform infrared spectrometer (FTIR) (Shimadzu) with Miracle 10 single reflection ATR accessory was used to record the FTIR spectra of the weld zone as well as welded zone after etching with oxidizing agent. The DSC thermograms of the weld zone as well as weld zone after etching with oxidizing agent were obtained using a differential scanning calorimetry (TA Instrument DSC2920). The weight range of the samples was taken between 2 and $3 \mathrm{mg}$ from the weld line. Heating rate of the samples was $10^{\circ} \mathrm{C} /$ min under pure nitrogen and then cooled down to $25^{\circ} \mathrm{C}$ at the same rate. Second scan was performed for both samples at the same condition and that was used to calculate the crystallinity of welded zone using the following formula:

$$
\text { Crystallinity of HDPE pipe }=\frac{\Delta H_{m}}{\Delta H_{m}{ }^{\circ}},
$$

where $\Delta H_{m}{ }^{\circ}$ is the heat of fusion of $100 \%$ crystalline HDPE and $\Delta H_{m}$ is the melting enthalpy of the welded zone of HDPE pipe.

Scanning electron microscope (SEM, JSM-6700, JEOL, Japan) was used for the observation of the tensile fracture surfaces of selected specimens as well as surface etched weldments. Similar to the weldment etching, the fracture surface was also etched by potassium permanganate based etchant and compared with unetched samples. The weld seams at standard welding condition (W-PE10) were etched using potassium permanganate as well as chromium trioxide based etchants, separately. The weld seam of W-PE70 was also etched using chromium trioxide/sulfuric acid for the comparison with W-PE10. The etched samples and fracture surfaces of weld were coated with gold for surface examination under SEM. This study revealed that the welding condition of PE pipes clearly reflected on the morphology and mechanical properties of butt joint.

\section{Results and Discussion}

The mechanical property of polyethylene depends on crystallinity, polymer chain entanglement, tie molecule density, and morphology (including spherulite size and lamellar thickness); and these are influenced by thermal history and any subsequent processing including welding [1]. Figure 2 shows weld seam of the (a) W-PE10, (b) W-PE60, and (c) WPE70 and the corresponding notched bar type samples after tensile test in (d), (e), and (f), respectively. The welded zone was clearly visible after etching with potassium permanganate based etchant at room temperature for 1 day. The joint of HDPE pipes clearly showed the variation on the structure with increasing the fusion time even by the naked eyes. The partially fused weld line was observed in W-PE70 due to insufficient diffusion of PE chains. Here, the optical images of the fracture surface of butt joint showed structural variation with increasing the fusion time. In the previous reports, a mixture of $\mathrm{H}_{2} \mathrm{SO}_{4}$ and $\mathrm{KMnO}_{4}$ was found very effective for the oxidation and etching of carbon nanomaterials as well as opening of carbon nanotubes [17-22]. So, in this study, $\mathrm{KMnO}_{4}$ based etchant was employed and the interesting microstructure of weld zone was observed. Scanning electron microscopy was used for more detailed understanding of the fracture surface of the weld zone before and after etching with $\mathrm{KMnO}_{4}$ based etchant. It was quite easy to differentiate the fracture surface of the butt welded samples with the variation of fusion time due to the changes in the PE chains entanglement at the joint. Figures 3(a) and 3(b) show the SEM images of the tensile fracture surface of W-PE10 at different magnifications, where we observed spherulites at the weld zone [23]. After etching the tensile fracture surface, the fibrils at the weld zone were completely changed into 


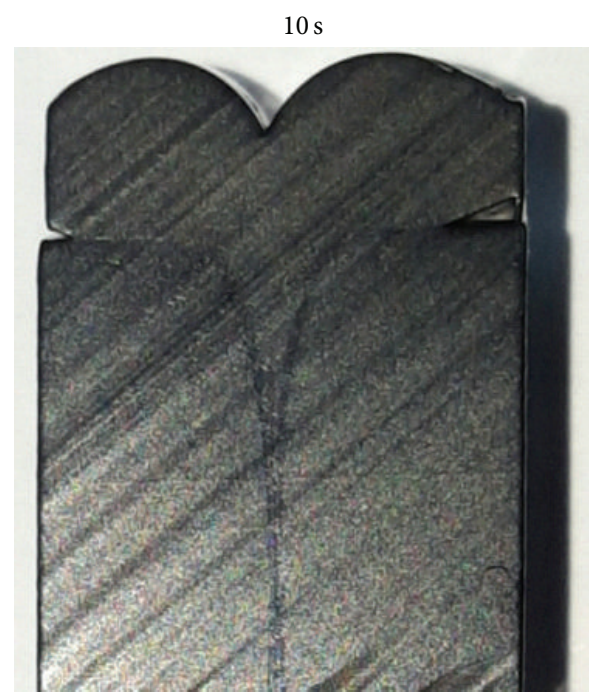

(a)

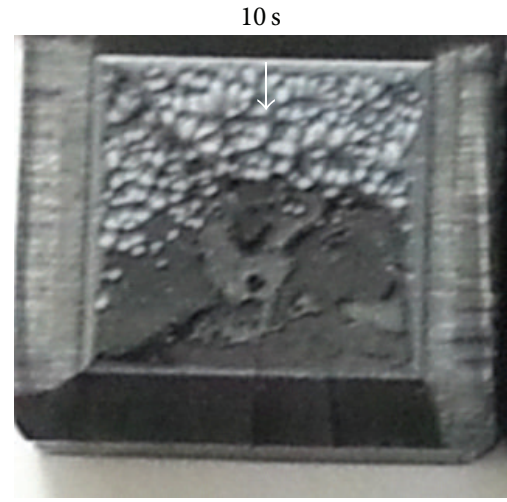

(d)

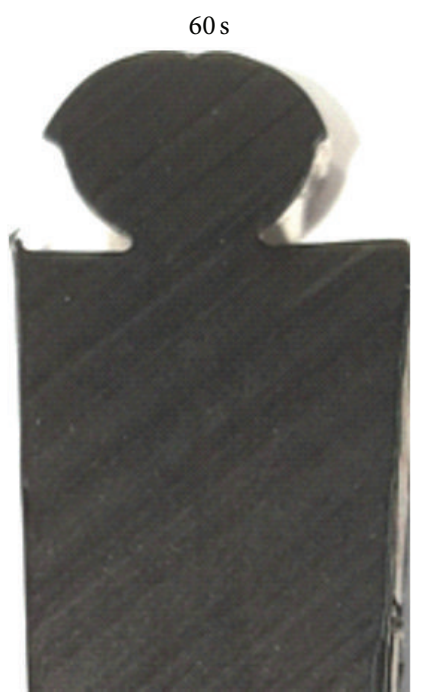

(b)

$60 \mathrm{~s}$

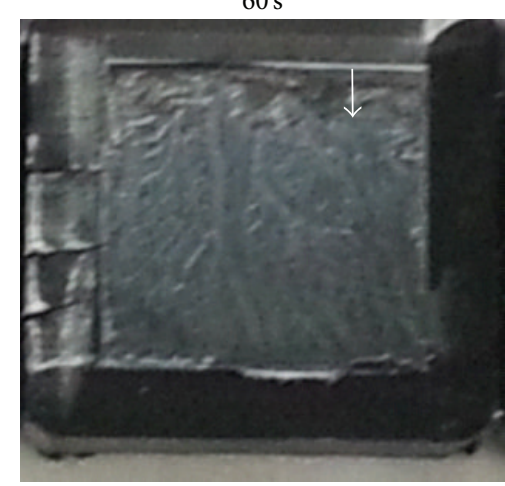

(e)

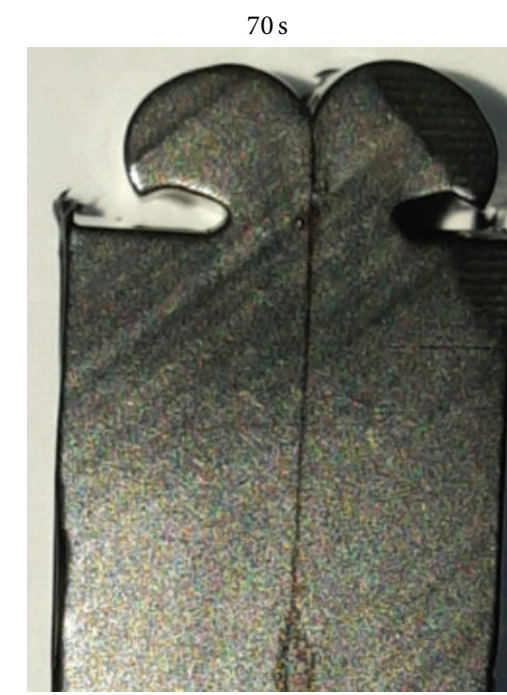

(c)

$70 \mathrm{~s}$

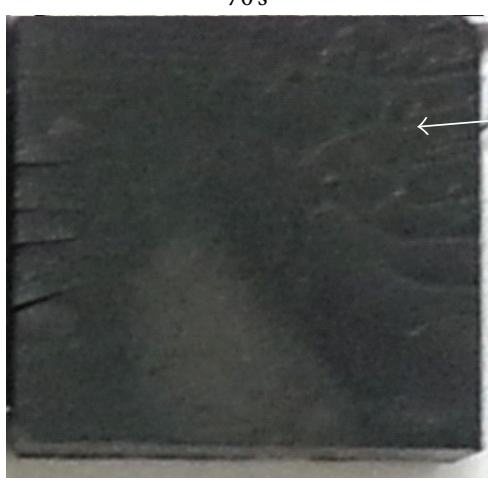

(f)

FIGURE 2: Optical image of the weld seam for (a) W-PE10, (b) W-PE60, and (c) W-PE70. The pictures of weld seams of HDPE pipes were taken after etching the weldment using potassium permanganate based etchant for 1 day. Full-notch tensile fracture surface of butt joint for (d) W-PE10, (e) W-PE60, and (f) W-PE70.

flat surface with some small voids as shown in Figures 3(c) and $3(\mathrm{~d})$. The formation of completely diffused interface was possible due to sufficient entanglement of polymer chain as in the parent material at the standard welding condition. Figures 4(a) and 4(b) show the SEM images of W-PE60 at different magnifications in which the morphology of the weld zone is completely different than W-PE10. Here, the degree of the chain entanglement is not enough for the formation of completely diffused interface at the joint because of low temperature during welding. After etching the fracture surfaces of W-PE60, the weld zone showed two different sceneries in Figures 4(c) and 4(d) due to the association of cold fusion flaws (large flat zones) as well as partially diffused polymer chains (smooth holes). Here, insufficient chain entanglements across the weld interface are supporting catastrophic chain pullout resulting in the decrease of joint strength [24-27]. Furthermore, even a visually acceptable fusion weld can appear in cold fusion, lacking the reliability to maintain operating pressures for the total of its design life which is found due to the insufficient entanglement of the PE chains across the joint interfaces. SEM images of the tensile fracture surface of W-PE70 in Figures 5(a) and 5(b) show different morphologies compared to the standard welding condition due to the close molecular contact without sufficient interdiffusion of chain segments across the wetted interface. After etching the W-PE70, we clearly observed incompletely diffused interfaces (arrow lines) and remaining close molecular contact interfaces. At last, with increasing the cooling time before pressure created for fusion of the pipes, the temperature at the heated end faces of the pipe decreases and there are no sufficient chain entanglements across the newly developed joint interface and that creates insufficient chain entanglements; thus the catastrophic chain pullout occurs at the interface. The increased interfacial strength before saturation is proportional to the number of interfacial entanglements between chains from opposite sides.

Figures 6(a), 6(b), 6(c), and 6(d) display the $\mathrm{H}_{2} \mathrm{SO}_{4} / \mathrm{KMnO}_{4}$ etched weldment at different magnifications where the amorphous region of PE was more susceptible to the oxidizing agent and as a result many ditches in the weld 


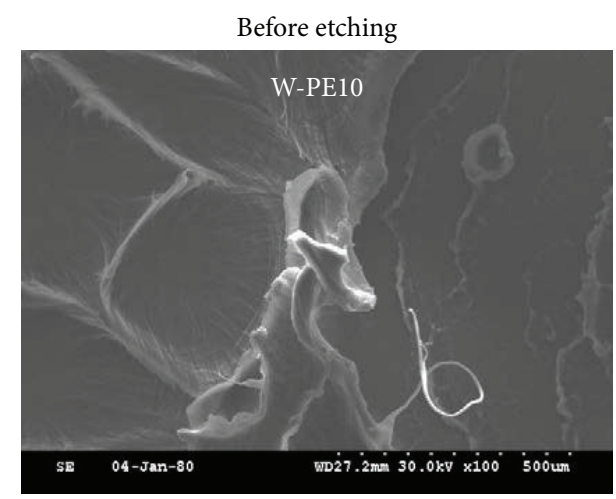

(a)

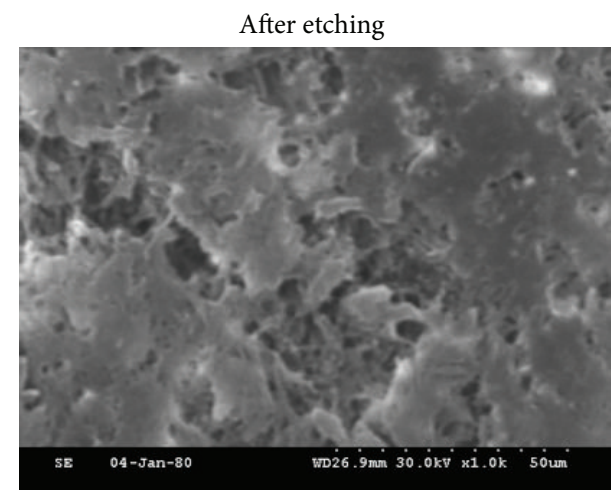

(c)

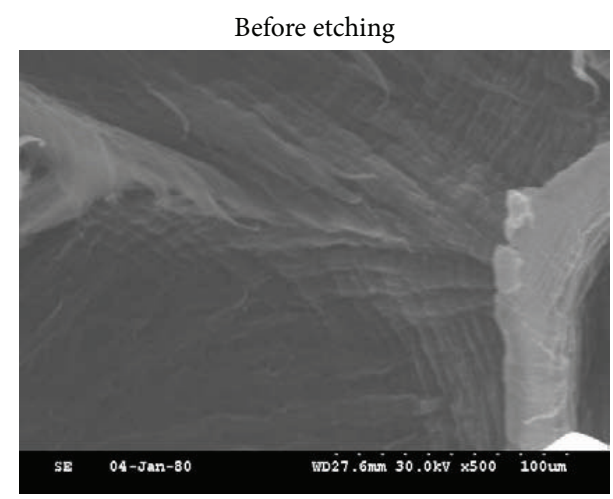

(b)

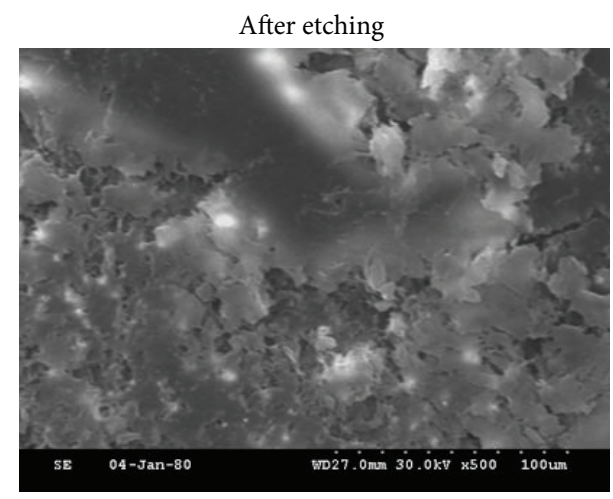

(d)

FIGURE 3: SEM images of the tensile fracture surface of W-PE10 $(a, b)$ near to crack initiation point and W-PE10 after etching with potassium permanganate based etchant (c, d). Scale bar is $500 \mu \mathrm{m}$ (a, c) and $100 \mu \mathrm{m}(\mathrm{b}, \mathrm{d})$.

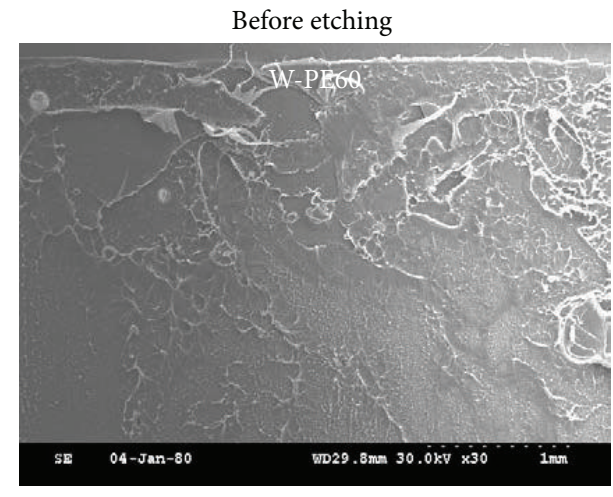

(a)

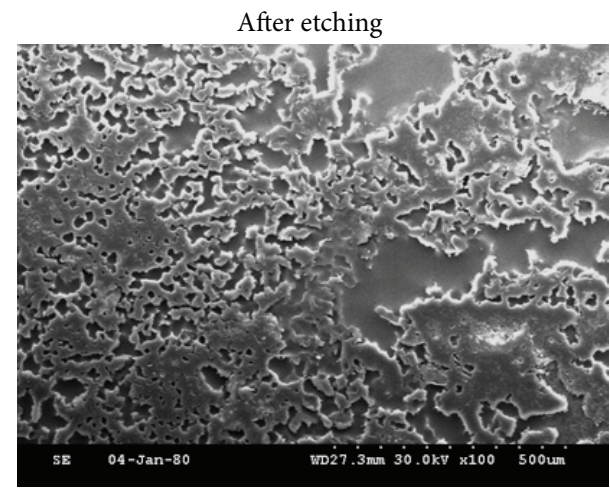

(c)

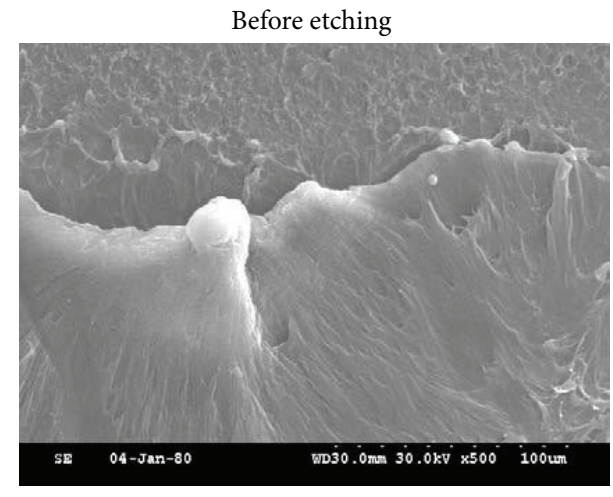

(b)

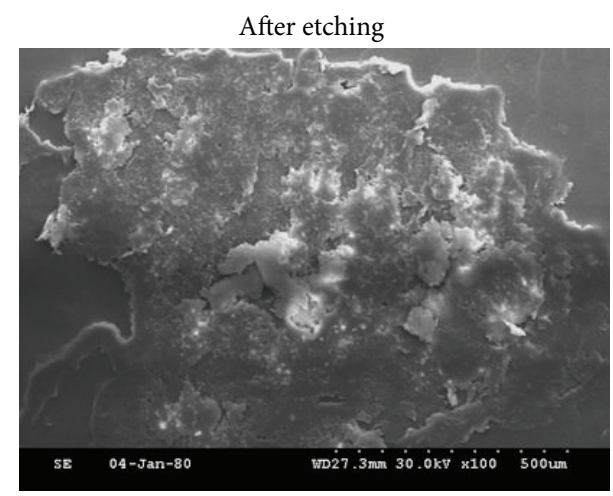

(d)

FIGURE 4: SEM images of the tensile fracture surface of W-PE60 $(a, b)$ near to crack initiation point and W-PE60 after etching with potassium permanganate based etchant (c, d). Scale bar is $1 \mathrm{~mm}(\mathrm{a}), 100 \mu \mathrm{m}(\mathrm{b})$, and $500 \mu \mathrm{m}(\mathrm{c}, \mathrm{d})$. 


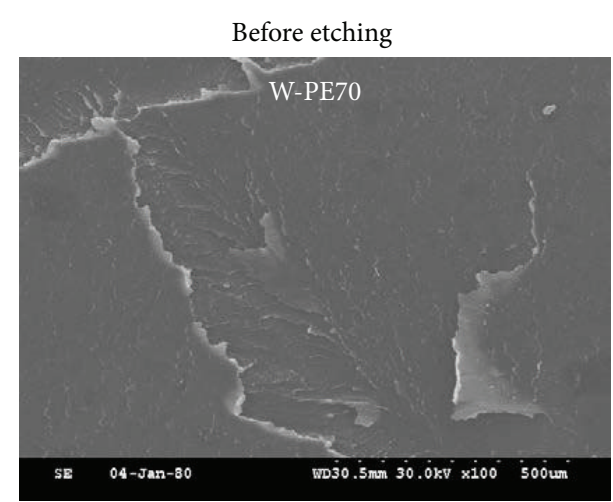

(a)

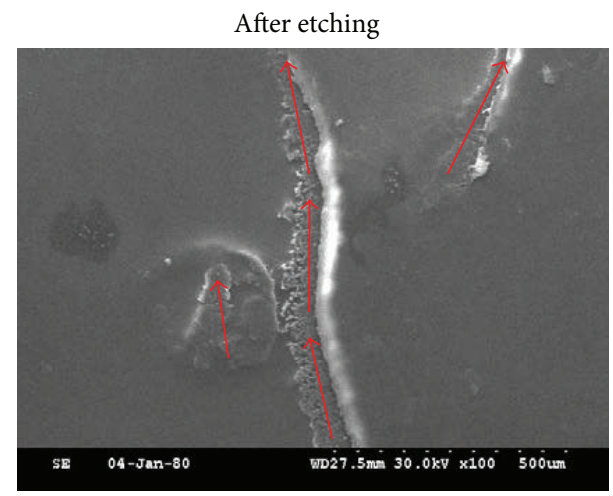

(c)

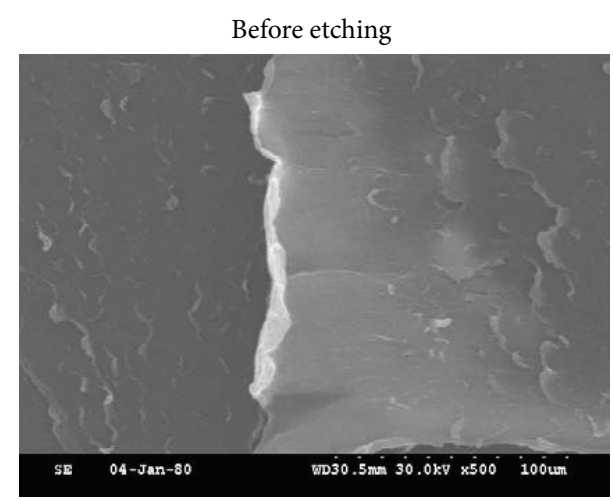

(b)

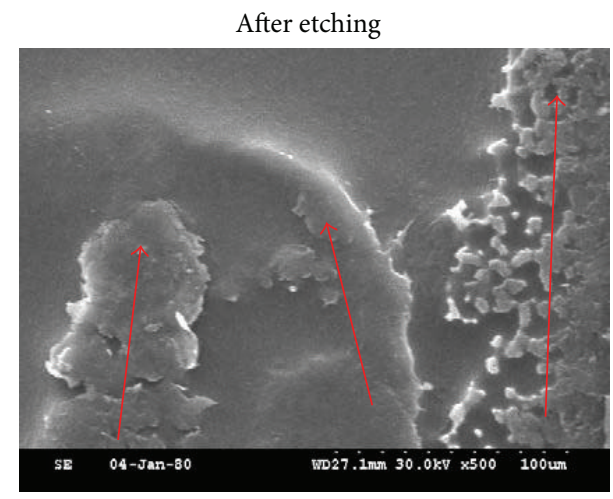

(d)

FIGURE 5: SEM images of the tensile fracture surface of W-PE70 $(a, b)$ near to crack initiation point and W-PE70 after etching with potassium permanganate based etchant (c, d). Scale bar is $500 \mu \mathrm{m}$ (a, c) and $100 \mu \mathrm{m}$ (b, d).

seam of PE pipe were observed. The size of pitting varied after the acid attack to the parent material and within the welds, preferential attack occurred at the weld edges and was greatest in the centerline with the distorted region as shown in Figure 6(c). Images of the lamellar profile of weld seam are shown in Figure 6(d) in which thread-like lamellae structure is built up by randomly banded spherulites. The banded spherulites were noticed to be more "thread-like" and more elongated in the ditches. In the previous report, etching of the weldment using a saturated solution of chromic trioxide in water showed higher susceptibility of welded region than the rest of the pipe $[23,24]$. The optical image of the weldment at standard welding condition is shown in Figure 7(a). SEM images of the weldment at different magnifications (Figures $7(\mathrm{~b}), 7(\mathrm{c}), 7(\mathrm{~d})$, and $7(\mathrm{e}))$ after etching with chromium trioxide based etchant were taken from the white rectangle of Figure 7 (a). Here, the weldment showed $\sim 20 \mu \mathrm{m}$ thick vertical dark line which is indicated by arrows (Figures 7(b) and 7(c)) and two different orientated structures at horizontal and vertical direction on the left and right side of that line. At high magnification (Figures 7(d) and 7(e)), large voids were observed ubiquitously on the surface of weldment due to the strong etching effect of chromium trioxide. We believe that the flow-line was developed at the weld zone with oriented crystallized morphology through the sheared melt due to the combined effect of partially melted zone and the heat affected zone [6]. After etching the W-PE10 using $\mathrm{KMnO}_{4}$ and chromium trioxide based etchants, we confirmed that both etchants are useful to understand the microstructure of the weld zone. In fact, $\mathrm{KMnO}_{4}$ based etchant was found effective for the deep penetration of the weld seam while chromium trioxide based etchant showed the diffuse interface between the two different oriented structures at the butt joint. Optical image at the joint of W-PE70 after etching by chromium trioxide based etchant is shown in Figure 8(a). The defects at the joint were visible during milling the weldment, so etching of W-PE70 was performed without further smoothing the surface using microtome. SEM images of W-PE70 at different magnifications are shown in Figures 8(b), 8(c), 8(d), and $8(\mathrm{e})$. The incomplete fusion line (remnant of skin) was clearly observed at the center of weldment due to cooling the end faces of pipe after removing the heater plate for $70 \mathrm{~s}$. Furthermore, a cold fusion at butt joint of polyethylene pipe was formed through the close molecular contact followed by insufficient interdiffusion of chain segments back and forth across the wetted interface.

DSC thermograms (cooling and second scan) of (a) WPE10 and (b) W-PE10 after etching with $\mathrm{H}_{2} \mathrm{SO}_{4} / \mathrm{KMnO}_{4}$ are shown in Figure 9, where small differences on crystallization and melting temperature were noticed. The area of melting peak and crystalline peak was altered by etching process 


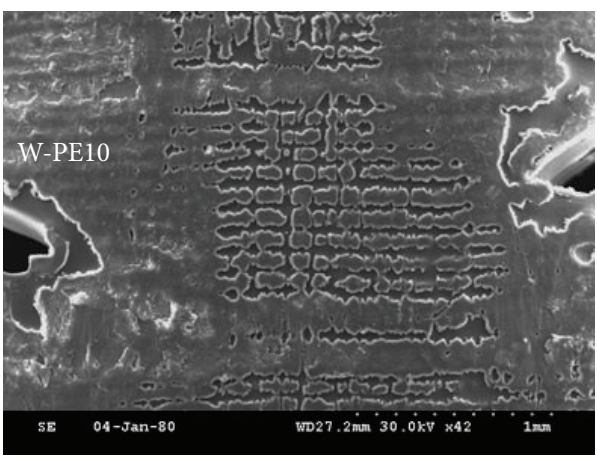

(a)

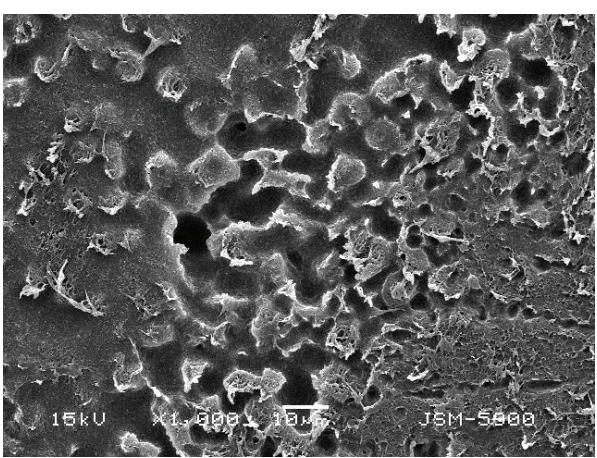

(c)

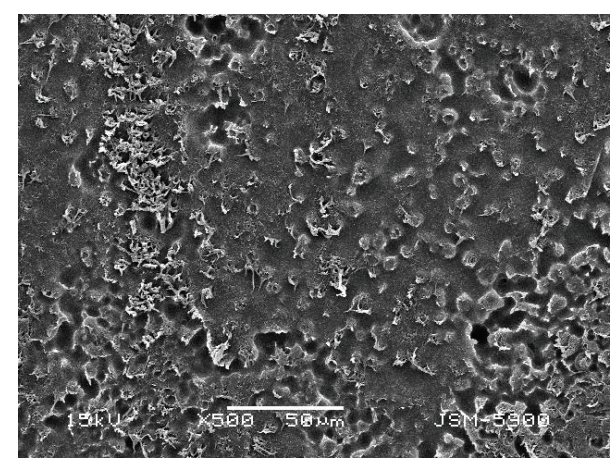

(b)

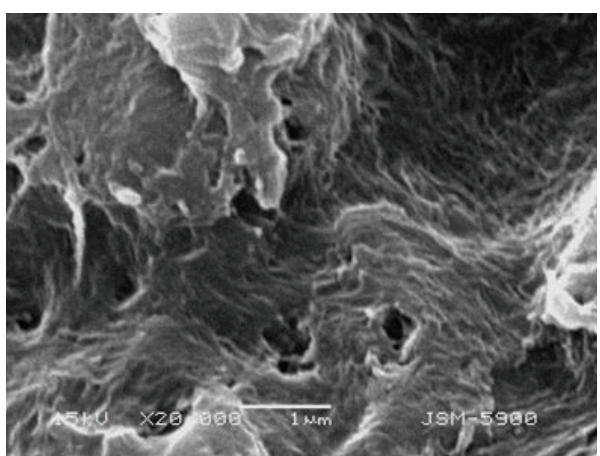

(d)

FIGURE 6: SEM images of W-PE10 weld seam area after etching by potassium permanganate based etchant $\left(\mathrm{KMnO}_{4} / \mathrm{H}_{2} \mathrm{SO}_{4}\right)$. Scale bar is $1 \mathrm{~mm}$ (a), $50 \mu \mathrm{m}$ (b), $10 \mu \mathrm{m}$ (c), and $1 \mu \mathrm{m}$ (d).

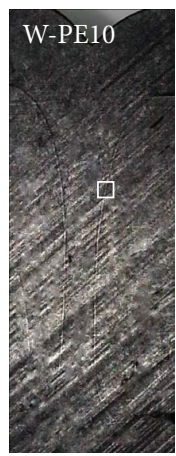

(a)

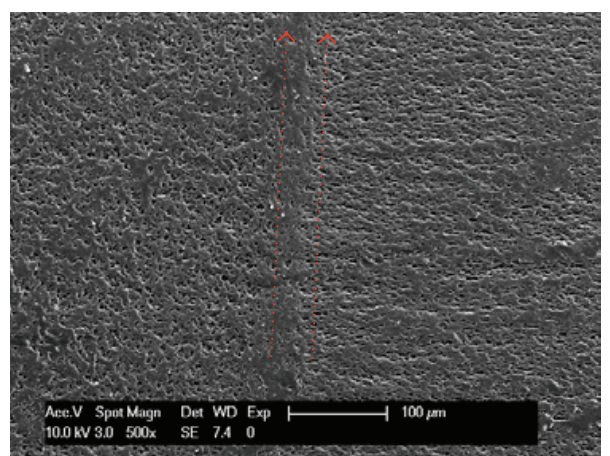

(b)

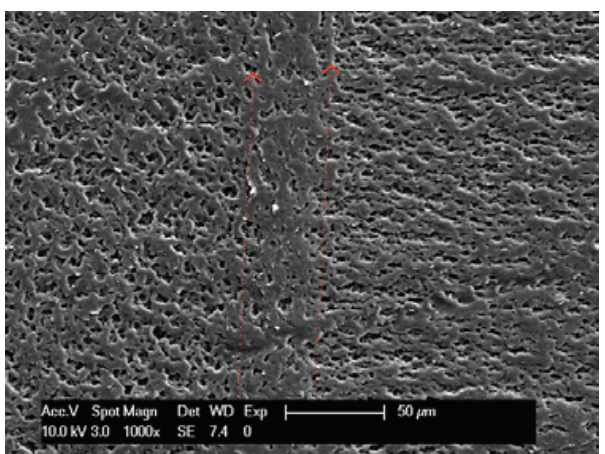

(c)

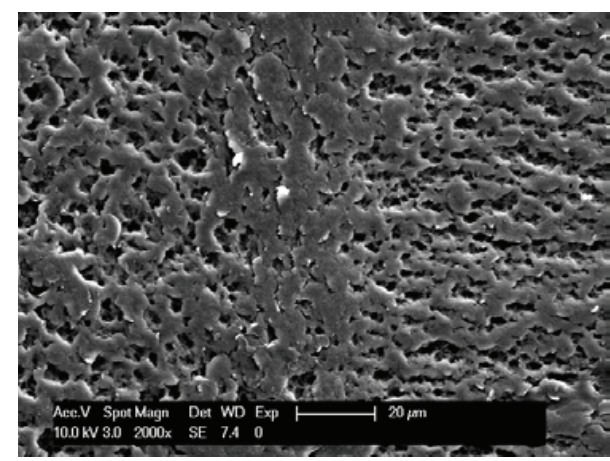

(d)

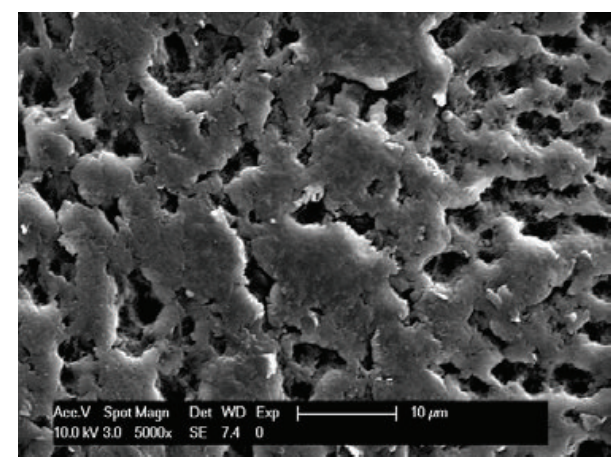

(e)

FIGURE 7: (a) Optical image of the W-PE10 weld seam after etching by chromium trioxide based etchant. SEM images of W-PE10 at different magnifications (b, c, d, e). Scale bar is $100 \mu \mathrm{m}$ (b), $50 \mu \mathrm{m}$ (c), $20 \mu \mathrm{m}$ (d), and $10 \mu \mathrm{m}$ (e). 


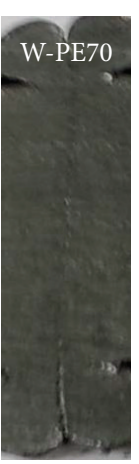

(a)

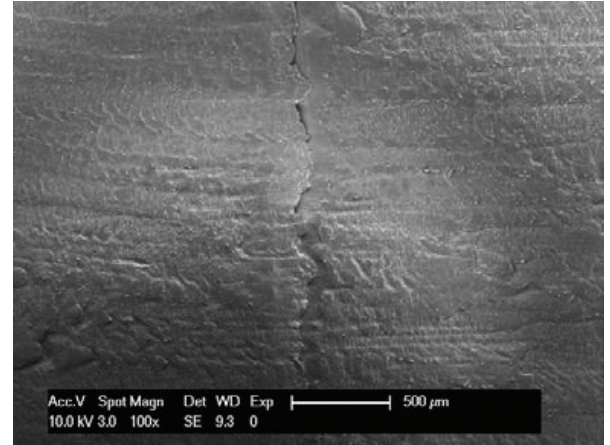

(b)

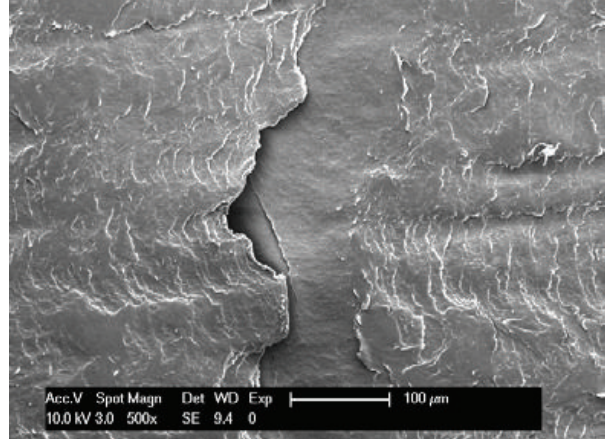

(c)

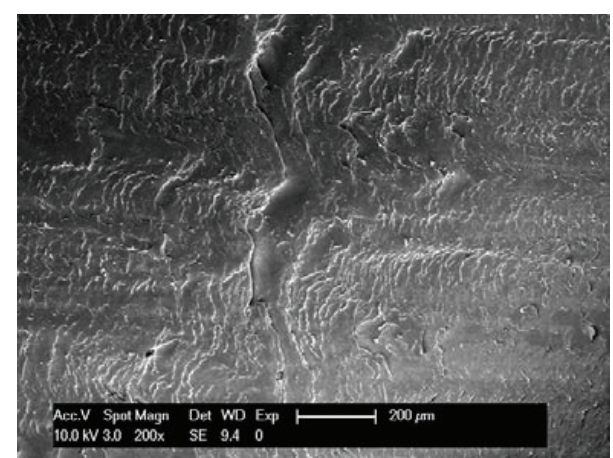

(d)

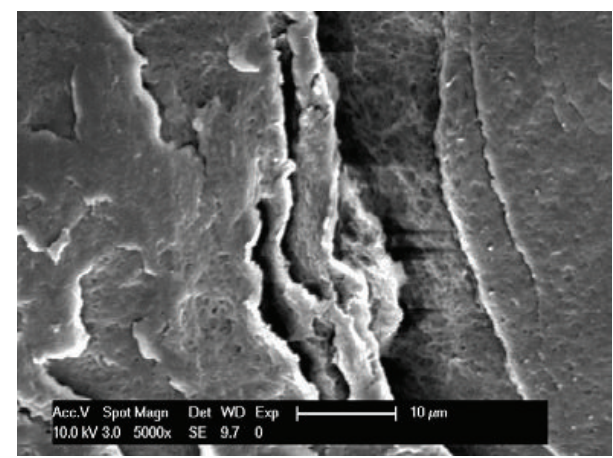

(e)

FIgURE 8: (a) Optical image of the W-PE70 weld seam after etching by chromium trioxide based etchant. SEM images of W-PE70 at different magnifications and different locations of weld zone (b, c, d, e). Scale bar is $500 \mu \mathrm{m}$ (b), $100 \mu \mathrm{m}$ (c), $200 \mu \mathrm{m}$ (d), and $10 \mu \mathrm{m}$ (e).

due to changing the amorphous and crystalline phase at the weld zone. HDPE pipe used in this study possesses approximately $48.5 \%$ amorphous phase and $51.5 \%$ plate-like crystalline phase (lamellae) [28, 29]. Interestingly, etching of weld seam using $\mathrm{H}_{2} \mathrm{SO}_{4} / \mathrm{KMnO}_{4}$ improved the crystallinity of weld zone to $57.10 \%$ due to higher susceptibility of the amorphous phase of PE than lamellae. FTIR spectroscopy has been already used to observe surface oxidation of $\mathrm{PE}$ pipes. Usually, carbonyl absorption peak can be detected at $\sim 1730 \mathrm{~cm}^{-1}$ for the oxidized PE pipe [30]. FTIR spectra of (a) W-PE10 and (b) W-PE10 after etching with $\mathrm{H}_{2} \mathrm{SO}_{4} / \mathrm{KMnO}_{4}$ are shown in Figure 10. Here, W-PE possessed bands at $2917 \mathrm{~cm}^{-1}, 2848 \mathrm{~cm}^{-1}, 1468 \mathrm{~cm}^{-1}$, and $730 \mathrm{~cm}^{-1}$ due to $\mathrm{CH}_{2}$ asymmetric stretching, symmetric stretching, bending deformation, and rocking deformation, respectively [31]. Even though the oxidation process occurred during the etching of weld seam by using $\mathrm{H}_{2} \mathrm{SO}_{4} / \mathrm{KMnO}_{4}$, any additional weak bank of carbonyl group at $\sim 1730 \mathrm{~cm}^{-1}$ was not observed. This indicated that the amorphous phase of PE was oxidized and removed during washing the etched weldment using water and acetone.

In the earlier reports, the mechanical strength at the polymer-polymer interface with the welding time had been investigated using simulations in which the interfacial strength saturates at the bulk shear strength much before polymers diffuse by their radius of gyration $\left(R_{g}\right)[10,27,28]$. The major failure mode alters from chain pullout at the interface to chain scission as in the bulk. To seize catastrophic chain pullout at the interface, sufficient chain entanglements across the interface are required for the strength increase [10]. Furthermore, when the density of entanglements at the interface reaches the bulk value, the bulk response is recovered for the required development of interfacial strength. The strength of joint depends on the fundamental materials properties as well as the engineering conditions imposed in a realistic welding process. Ezekoye et al. [10] used a model that emphasized the importance of examining heat transfer effects in any polymer welding process. For joining polymeric elements through thermal welding, two polymer surfaces are brought into close contact above their melting temperature $\left(T_{m}\right)$ and are allowed to interdiffuse for a welding time $\left(t_{w}\right)$. Based on the polymer melt dynamics for homopolymer melts, the chains at the weld zone should diffuse by about their radius of gyration $\left(R_{g}\right)$; thus the properties of the weld are indistinguishable from those of the bulk once [24]. $R_{g}$ is useful to estimate the size of a polymer coil of a given molecular weight, Mw. The pipe grade PE4710 used in this study is made by the conglomeration of polymer chains with a broad mix of $\mathrm{Mw}$ (lengths); hence interfacial thickness (across the plane of cocrystallization) was estimated in the order of 15-30 nm using some basic calculations. During butt welding of HDPE pipes, the thermally driven wriggling of the molecular chain facilitates mutual polymer chain diffusion of one interface into the other. Generally, the diffusion plane has a thickness within the range of $15-100 \mathrm{~nm}$. The interfacial thickness $(15-30 \mathrm{~nm})$ is very thin section and difficult to 

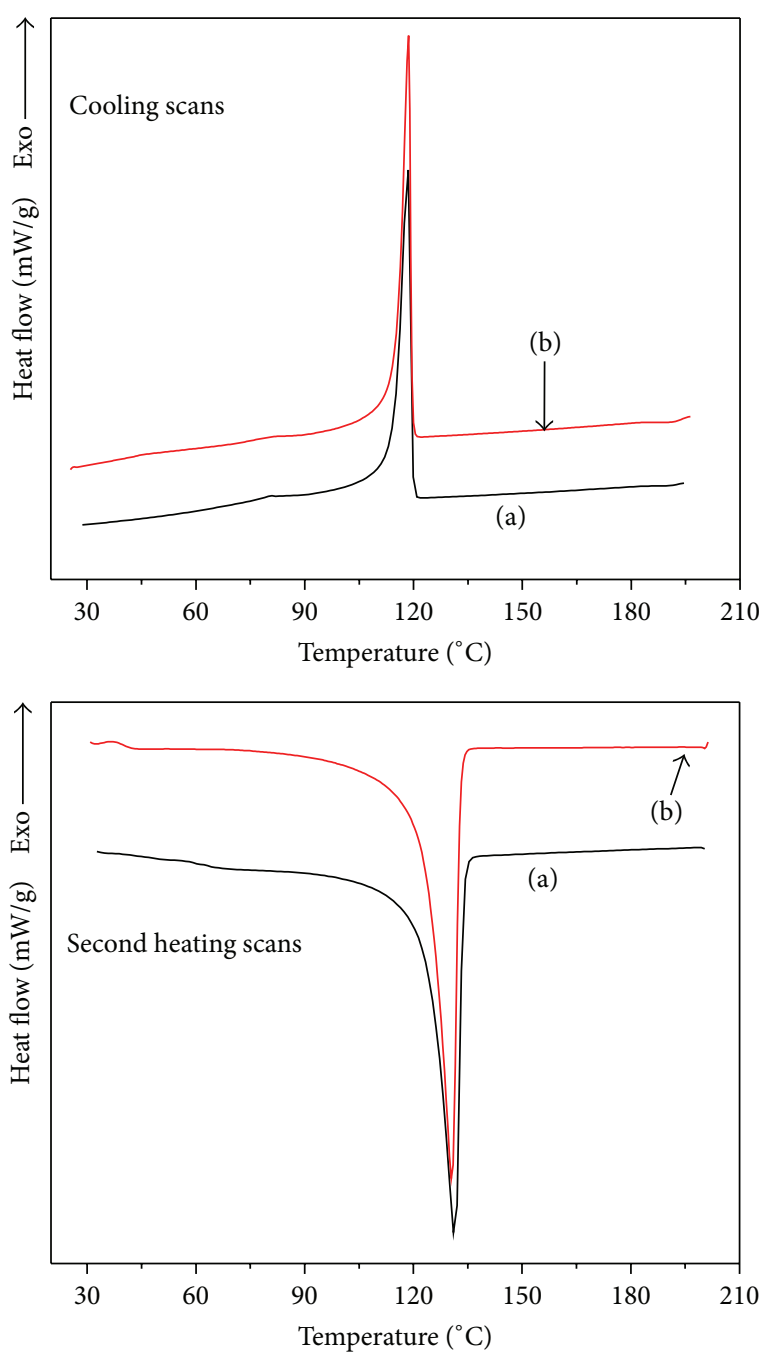

FIGURE 9: DSC thermograms of (a) W-PE10 and (b) W-PE10 after etching with potassium permanganate based etchant.

evaluate diffusion entanglement fusion quality using FNCT or PENT. The diffusion plane may not even be perfectly "flat," and the tip of the razor may even be wider than $50 \mathrm{~nm}$. Furthermore, it is quite complex to differentiate the expected strengthening mechanisms at the joint with the proper experimental results because of difficulties to observe chain entanglements by SEM measurement. However, we analyzed the fracture surfaces of butt joint as well as weld seam after etching of specimens obtained from different fusion times. The major failure mode was found to be chain scission at the standard welding condition as in the bulk rather than chain pullout $[10,24]$. In our experiment, the interfacial strength decreased largely for W-PE70 due to insufficient entanglement of polymer chains at the joint interface. At the standard welding condition, the dominant failure mechanism changed from chain pullout at small $t_{w}$ to chain scission at large $t_{w}$ and the diffusion time $\left(t_{d}\right)$ for the chains to diffuse a distance $R_{g}$. The rheological, dynamic, and fracture properties of PE can be determined based on the

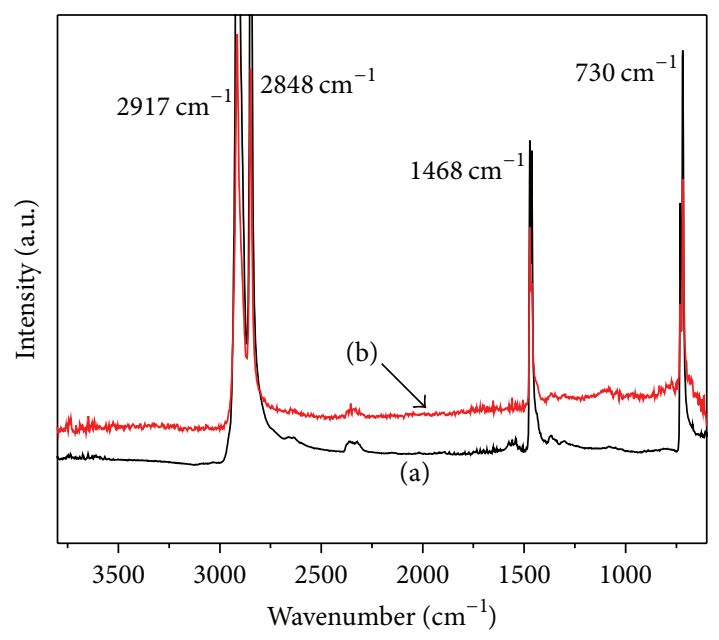

FIGURE 10: FT-IR spectra of (a) W-PE10 and (b) W-PE10 after etching with potassium permanganate based etchant.

interpenetration of random coil of PE chains, that is, chains entanglements [24]. Fracture process in polymer is related to transmission of forces from unit area (stress). To study cold fusion flaws, in this work, weak molecular structure was created at the joint by increasing the cooling time before pressure created for fusion; as a result the decrease of the transmitting such force was caused by insufficient polymer entanglement. Figure 11(a) shows the diffusion of polymer chains across weld interface at standard welding condition, where sufficient PE chain entanglements are possible to bear the stress similar to base pipe material. On the other hand as shown in Figure 11(b), there is no proper diffusion of PE chains that is caused by partial cooling of melted PE chains before fusion; consequently incomplete entanglements of chain are responsible for generating cold fusion flaws at the joint. Formation of cold fusion flaws is more elaborated in Figure 12 comparing the $\mathrm{PE}$ chain entanglements at weld zone for (a) standard (WPE-10) and (b) nonstandard (W-PE60/WPE70) conditions. During standard welding condition, the bridge and chain intersecting at weld line (Figure 12(a)) should resemble the base material due to the existence of an entanglement network in an isotropic concentrated melt. Furthermore, a bridge is a segment of chain which crosses the weld line and capable of transmitting forces across the weld line plane in the melt for a time dependent on the relaxation of this chain segment.

In W-PE70 (Figure 12(b)), incomplete entanglements of chains were responsible for generating cold fusion flaws in butt joint through the close molecular contact (van der Waals) followed by insufficient interdiffusion of chain segments across the wetted interface. However, the applied pressure largely affects the orientation of PE chain at the weld zone, so further research is required to explain the orientation of PE chains at the weld zone during the butt fusion welding.

Figure 13 shows the tensile test of fully notched bar type specimens of (A) W-PE10, (B) W-PE30, and (C) W-PE60. Here, the yield strength and displacement of the specimens 

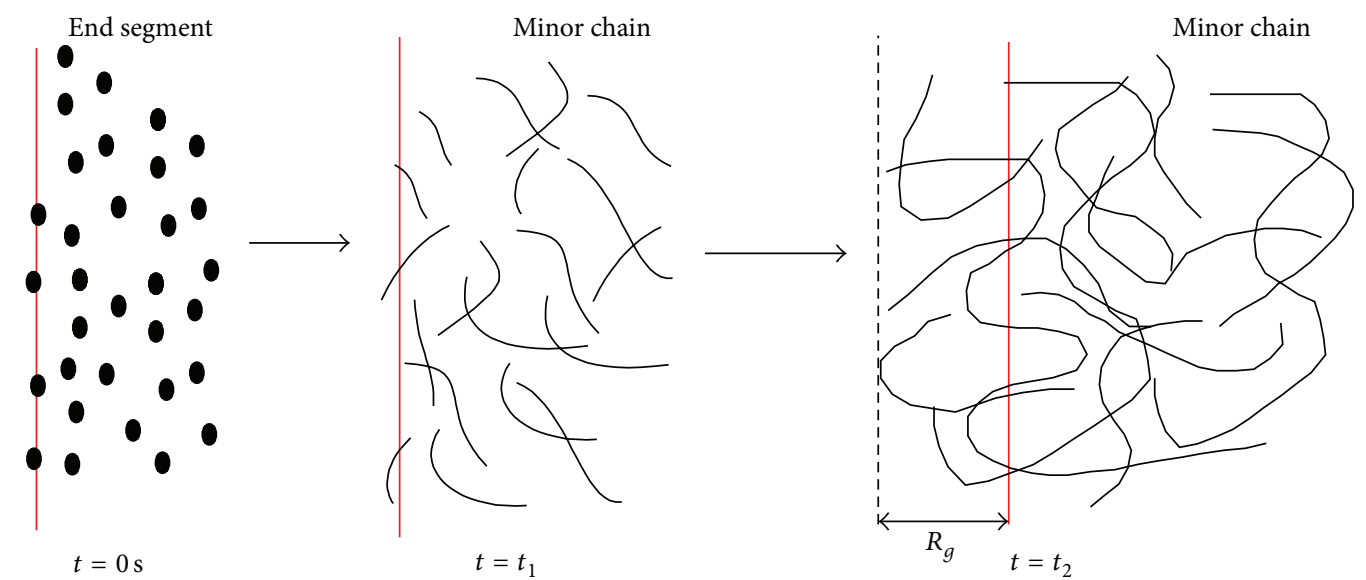

(a)
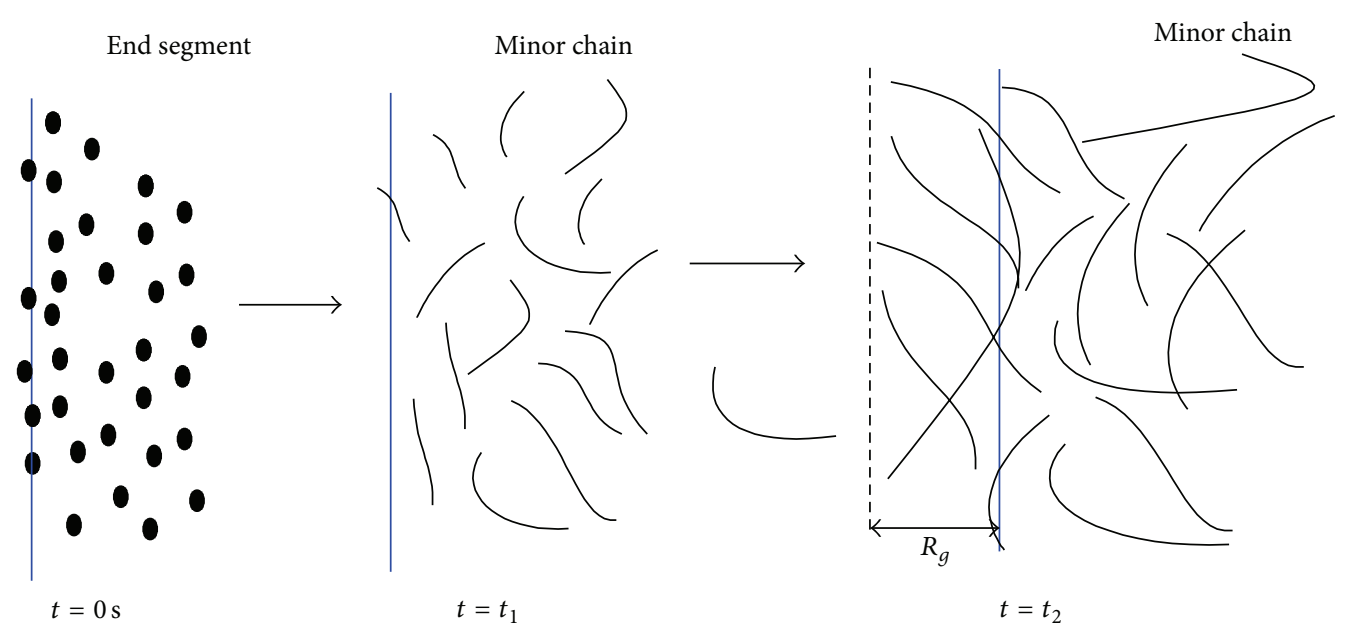

(b)

FIGURE 11: (a) Diffusion of polyethylene chains across weld interface at standard welding condition. (b) Partial diffusion of polyethylene chains across weld interface during cold fusion. The illustration shows evolution of minor chains from interface wetting until chains have diffused an average distance equal to the radius of gyration, adapted from Ezekoye et al. [10].

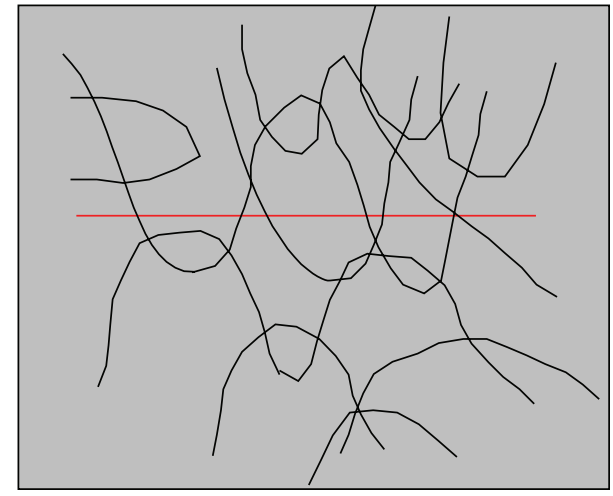

(a)

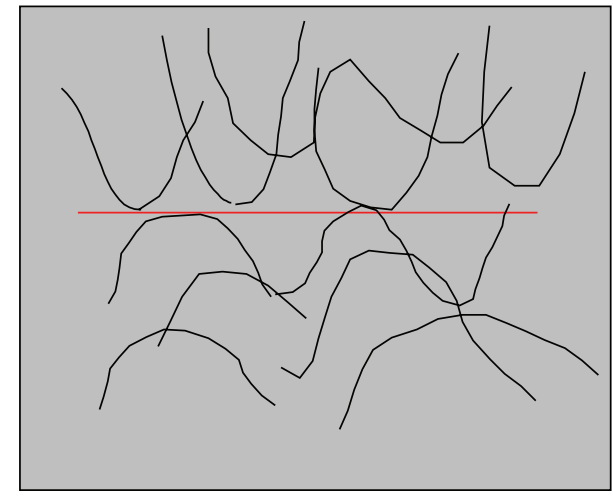

(b)

FIGURE 12: Entanglements in a polymer melt of weld zone at (a) standard condition and (b) cold fusion, adapted from Wool [24]. 


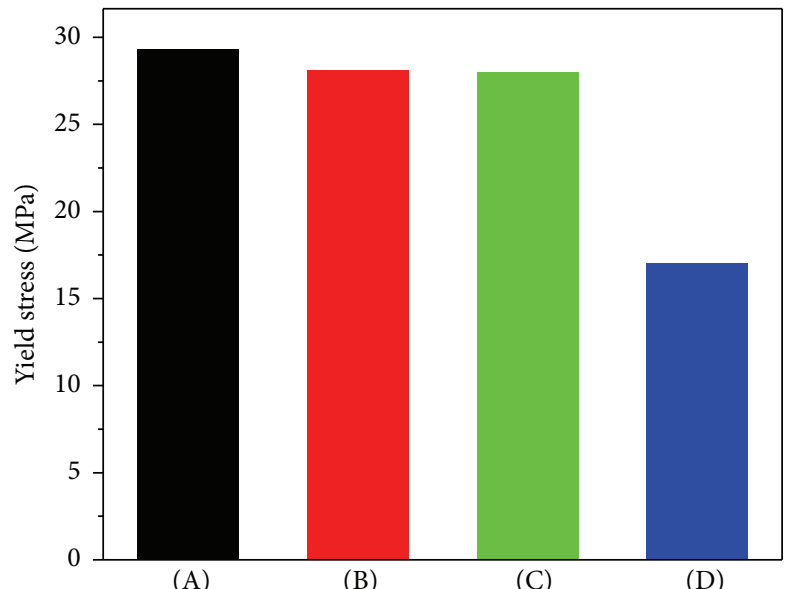

(a)

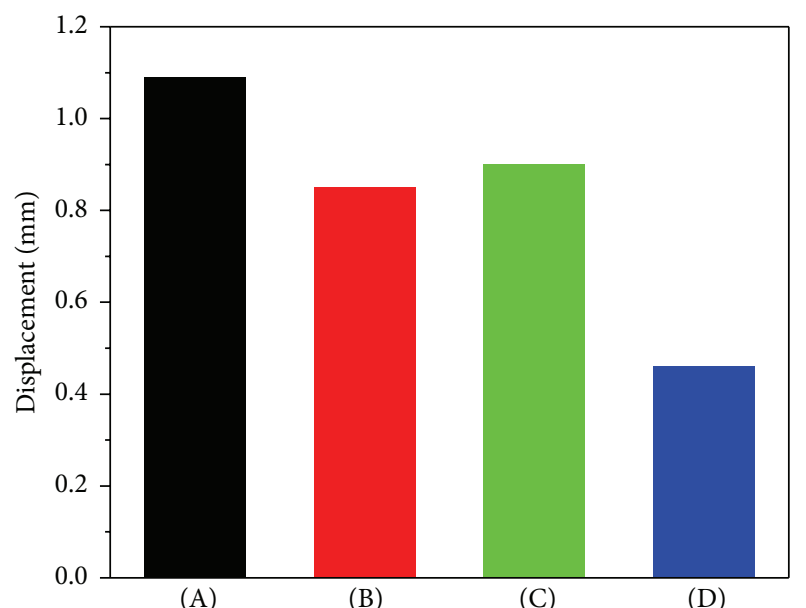

(b)

FIGURE 13: Plot of yield stress (a) and displacement (b) obtained from the tensile test of full-notched specimen: (A) W-PE10, (B) W-PE30, (C) W-PE60, and (D) W-PE70.

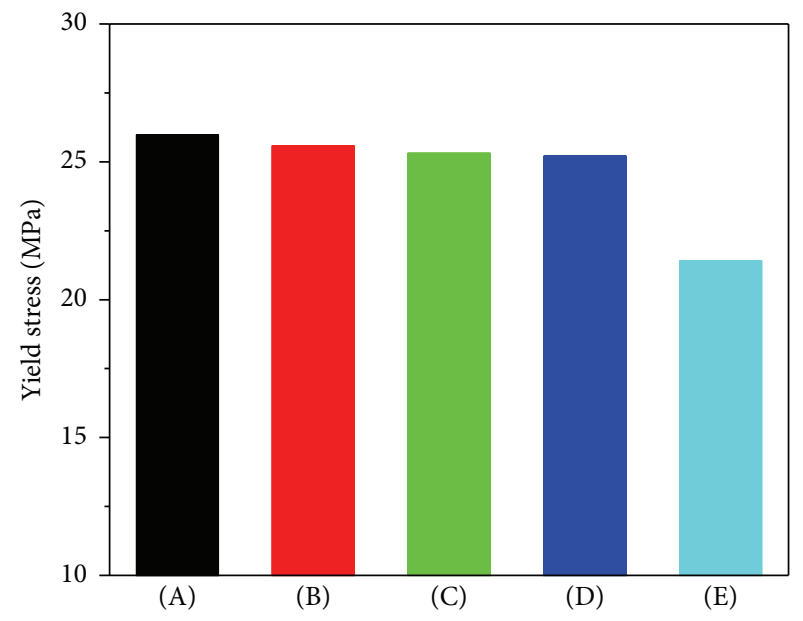

(a)

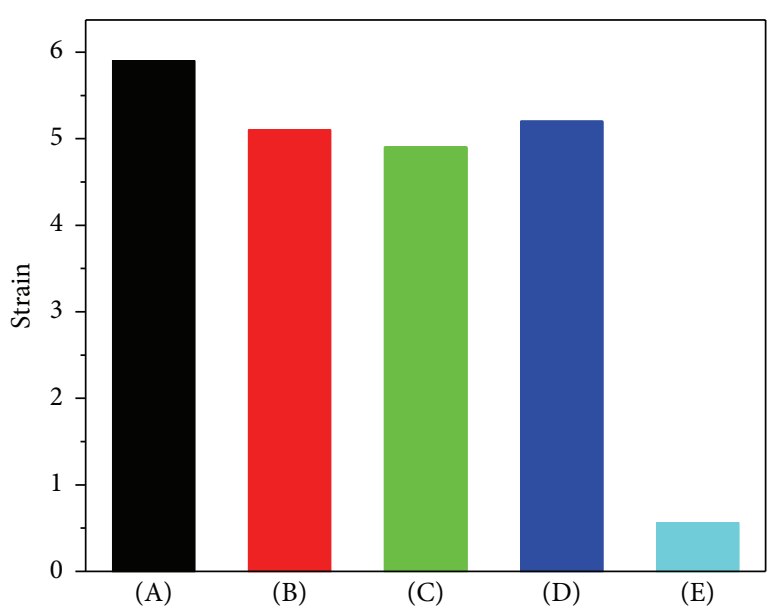

(b)

FIGURE 14: Plot of yield stress (a) and displacement (b) obtained from the dog-bone shaped specimens: (A) parent pipe without welding, (B) W-PE10, (C) W-PE30, (D) W-PE60, and (E) W-PE70.

made out from the welded pipes at standard condition (WPE10) were observed slightly higher until W-PE60. For WPE70, the value of the yield strength and displacement was found significantly lower than that for W-PE10, W-PE30, and W-PE60. Even the tensile fracture surface morphology of W-PE60 showed significant differences compared to WPE10; only W-PE70 showed significantly lower value of the yield strength and displacement. This indicates that only very poor quality of weld can be identified by tensile test of fully notched specimens. Furthermore, small defects in the joint caused by molecular entanglement at the newly developed interface cannot be identified by fully notched tensile test. Additionally, W-PE70 was tested without notch and the quantitative comparison with other fully notched specimens might not be reliable. So, for more clarification of the weld quality, tensile test of the dog-bone shaped samples at different welding conditions was also performed at room temperature [32]. Figure 14 displays the yield strength and strain of (A) nonwelded pipe, (B) W-PE10, (C) W-PE30, (D) W-PE60, and (E) W-PE70, which were extracted from stressstrain curves of dog-bone shaped specimens. Except slight variation on the strain, the yield strength values of W-PE10, $\mathrm{W}-\mathrm{PE} 30$, and W-PE60 were found almost the same. Only, W-PE70 showed large differences on the yield stress and strain compared to the other samples. Next, the nonwelded as well as welded pipes at different fusion time after round U-notch were used for tensile test. The stress-displacement curves of U-notched specimens from (a) nonwelded pipe, (b) W-PE10, (c) W-PE30, (d) W-PE60, and (e) W-PE70 are shown in Figure 15. We found quite differences on the yield strength and displacement among the butt joints at different fusion time (Table 1). Particularly, the strain energy decreased 
TABLE 1: Yield strength and displacement of butt joints at different welding conditions of the HDPE pipes obtained from round U-notched tensile test.

\begin{tabular}{lccc}
\hline Material code & Heat plate removal time plus time to achieve fusion $(\mathrm{s})$ & Yield strength (MPa) & Displacement (mm) \\
\hline PE parent & Without welding & $25.40 \pm 0.60$ & $43.91 \pm 1.2$ \\
W-PE10 & 10 & $24.37 \pm 0.48$ & $39.73 \pm 1.7$ \\
W-PE30 & 30 & $25.01 \pm 0.70$ & $23.51 \pm 0.9$ \\
W-PE60 & 60 & $23.6 \pm 0.82$ & $13.68 \pm 0.7$ \\
W-PE70 & 70 & $8.57 \pm 0.91$ & $1.27 \pm 0.50$ \\
\hline
\end{tabular}

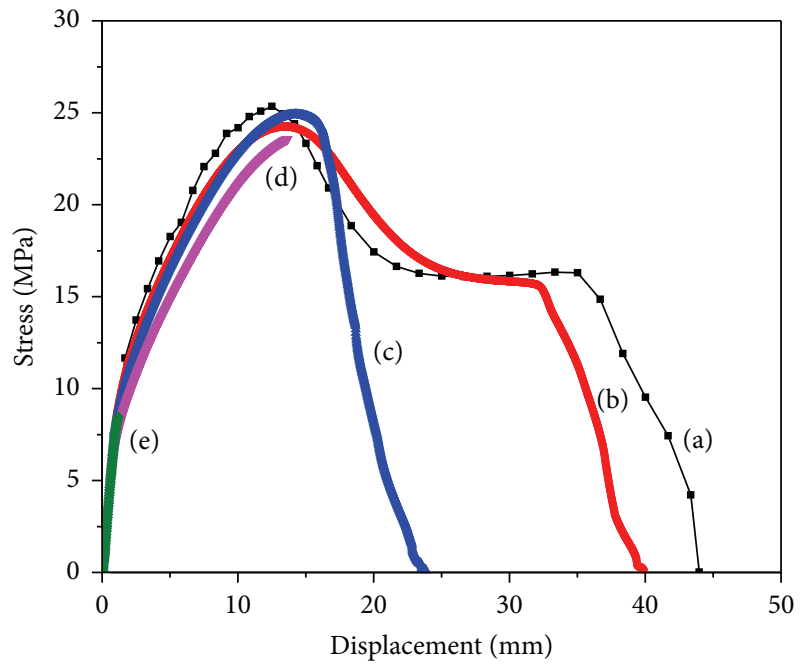

FIGURE 15: Stress-displacement curves of (a) parent pipe without welding, (b) W-PE10, (c) W-PE30, (d) W-PE60, and (e) W-PE70 obtained from the round $\mathrm{U}$-notched specimens.

significantly with increasing the fusion time from $10 \mathrm{~s}$ to $70 \mathrm{~s}$. These results quite matched with the surface morphologies of the butt joint. Finally, based on the above observation, incomplete entanglement of the PE chains across the joint faces affects the total projected life of joint. The appropriate correlation of the round U-notched tensile test and surface morphology of butt joint after etching conferred suitable hints about the cold fusion in butt joint of polyethylene pipes.

\section{Conclusions}

The butt fusion joints in HDPE pipes ( $\mathrm{SDR}=9, \mathrm{D}=110 \mathrm{~mm}$ ) were produced at $231^{\circ} \mathrm{C}$ with the variation of fusion time $(10 \mathrm{~s}$, $30 \mathrm{~s}, 60 \mathrm{~s}$, and $70 \mathrm{~s}$ ) after the removal of the heater plate for the understanding of the cold fusion during inappropriate welding condition. Butt fusion joint at standard condition was compared with the joints produced after increasing the cooling time before fusion of the pipes. Potassium permanganate and chromium trioxide based two etchants were used for etching the weldments and the tensile facture surfaces for the evaluation of the microstructure of weld zone at different fusion time. Here, the surface of weldment confirmed the insufficient diffusion of polymer chains with increasing the fusion time; as a result the cold fusion flaws at the joint were generated and that was responsible for the poor mechanical property. Etching of the weldment by potassium permanganate based etchant showed improvement of the crystallinity of weld zone owing to the less stability of amorphous phase of PE in the oxidizing medium. The threadlike lamellae structure in the randomly banded spherulites was observed after etching the interface of weld at standard condition. The incomplete entanglement of the PE chains across the joint faces with increasing fusion time affected the total projected life of the butt joint. The proper relationship of the U-notched tensile test with the surface morphology of butt joints at different fusion times after etching could direct appropriate hint about the butt joint quality.

\section{Competing Interests}

The authors declare that they have no competing interests.

\section{Acknowledgments}

The authors are grateful to Nuclear Power Core Technology Development Program of the Korea Institute of Energy Technology Evaluation and Planning (KETEP) and this paper was granted financial resource from the Ministry of Trade, Industry \& Energy, Republic of Korea (Project no. 20131510200400).

\section{References}

[1] C. Ageorges, L. Ye, and M. Hou, "Advances in fusion bonding techniques for joining thermoplastic matrix composites: a review," Composites Part A: Applied Science and Manufacturing, vol. 32, no. 6, pp. 839-857, 2001.

[2] A. Yousefpour, M. Hojjati, and J.-P. Immarigeon, "Fusion bonding/welding of thermoplastic composites," Journal of Thermoplastic Composite Materials, vol. 17, no. 4, pp. 303-341, 2004.

[3] B.-Y. Lee, J.-S. Kim, S.-Y. Lee, and Y. K. Kim, "Butt-welding technology for double walled Polyethylene pipe," Materials \& Design, vol. 35, pp. 626-632, 2012.

[4] K. Leskovics, M. Kollár, and P. Bárczy, "A study of structure and mechanical properties of welded joints in polyethylene pipes," Materials Science and Engineering A, vol. 419, no. 1-2, pp. 138143, 2006.

[5] S. M. Pimputkar, "Dependence of butt fusion bond strength of joining conditions for polyethylene pipe," Polymer Engineering and Science, vol. 29, no. 19, pp. 1387-1395, 1989.

[6] E. Schmachtenberg and C. Tüchert, "Long-term properties of butt-welded poly(propylene)," Macromolecular Materials and Engineering, vol. 288, no. 4, pp. 291-300, 2003. 
[7] V. K. Stokes, "Joining methods for plastics and plastic composites," Polymer Engineering \& Science, vol. 29, pp. 1310-1324, 1989.

[8] F. Tariq, N. Naz, M. A. Khan, and R. A. Baloch, "Failure analysis of high density polyethylene butt weld joint," Journal of Failure Analysis and Prevention, vol. 12, no. 2, pp. 168-180, 2012.

[9] T. H. Tra, "Effect of weld parameters on mechanical properties of the friction stir welding AA6063-T5," ASEAN Engineering Journal, vol. 4, pp. 73-81, 2011.

[10] O. A. Ezekoye, C. D. Lowman, M. T. Fahey, and A. G. HulmeLowe, "Polymer weld strength predictions using a thermal and polymer chain diffusion analysis," Polymer Engineering and Science, vol. 38, no. 6, pp. 976-991, 1998.

[11] P. Barber and J. R. Atkinson, "The use of tensile tests to determine the optimum conditions for butt fusion welding certain grades of polyethylene, polybutene-1 and polypropylene pipes," Journal of Materials Science, vol. 9, no. 9, pp. 1456-1466, 1974.

[12] J. S. Mackie and A. Rudin, "Electron microscopy of solventetched polyethylene surfaces," Journal of Polymer Science, vol. 49, no. 152, pp. 407-417, 1961.

[13] Y. Lu, D. M. Shinozaki, and S. Herbert, "Inhomogeneous deformation in welded high density polyethylene," Journal of Applied Polymer Science, vol. 86, no. 1, pp. 43-52, 2002.

[14] P. Barber and J. R. Atkinson, "Some microstructural features of the welds in butt-welded polyethylene and polybutene-1 pipes," Journal of Materials Science, vol. 7, no. 10, pp. 1131-1136, 1972.

[15] S. M. Stevens, "Structure evaluation of polyethylene and polypropylene hot plate welds," TWI Report 466, 1996.

[16] L. Huo, F. Qi, Y. Zhang, H. Jing, and X. Yang, "Study on the basic mechanical behaviors of high density polyethylene electrofusion welded joints at different temperatures," Journal of Materials Science and Technology, vol. 19, no. 6, pp. 603-606, 2003.

[17] H. Hiura, T. W. Ebbesen, and K. Tanigaki, "Opening and purification of carbon nanotubes in high yields," Advanced Materials, vol. 7, no. 3, pp. 275-276, 1995.

[18] P. Pokharel, Q.-T. Truong, and D. S. Lee, "Multi-step microwave reduction of graphite oxide and its use in the formation of electrically conductive graphene/epoxy composites," Composites Part B: Engineering, vol. 64, pp. 187-193, 2014.

[19] P. Pokharel, S. H. Lee, and D. S. Lee, “Thermal, mechanical, and electrical properties of graphene nanoplatelet/graphene oxide/polyurethane hybrid nanocomposite," Journal of Nanoscience and Nanotechnology, vol. 15, no. 1, pp. 211-214, 2015.

[20] P. Pokharel and D. S. Lee, "High performance polyurethane nanocomposite films prepared from a masterbatch of graphene oxide in polyether polyol," Chemical Engineering Journal, vol. 253, pp. 356-365, 2014.

[21] P. Pokharel and D. S. Lee, “Thermal and mechanical properties of reduced graphene oxide/polyurethane nanocomposite," Journal of Nanoscience and Nanotechnology, vol. 14, no. 8, pp. 57185721, 2014.

[22] P. Pokharel, B. Pant, K. Pokhrel et al., "Effects of functional groups on the graphene sheet for improving the thermomechanical properties of polyurethane nanocomposites," Composites Part B: Engineering, vol. 78, pp. 192-201, 2015.

[23] R. P. Wool, B.-L. Yuan, and O. J. McGarel, "Welding of polymer interfaces," Polymer Engineering and Science, vol. 29, no. 19, pp. 1340-1367, 1989.
[24] R. P. Wool, "Polymer entanglements," Macromolecules, vol. 26, no. 7, pp. 1564-1569, 1993.

[25] H. Zhang and R. P. Wool, "Concentration profile for a polymerpolymer interface. 1. Identical chemical composition and molecular weight," Macromolecules, vol. 22, pp. 3018-3021, 1989.

[26] B. Crist, C. J. Fisher, and P. R. Howard, "Mechanical properties of model polyethylenes: tensile elastic modulus and yield stress," Macromolecules, vol. 22, no. 4, pp. 1709-1718, 1989.

[27] M. Bousmina, H. Qiu, M. Grmela, and J. E. Klemberg-Sapieha, "Diffusion at polymer/polymer interfaces probed by rheological tools," Macromolecules, vol. 31, no. 23, pp. 8273-8280, 1998.

[28] V. Vijayan, P. Pokharel, M. K. Kang, and S. Choi, "Thermal and mechanical properties of e-beam irradiated butt-fusion joint in high-density polyethylene pipes," Radiation Physics and Chemistry, vol. 122, pp. 108-116, 2016.

[29] P. Pokharel, H. Bae, J.-G. Lim, K. Y. Lee, and S. Choi, "Effects of titanate treatment on morphology and mechanical properties of graphene nanoplatelets/high density polyethylene nanocomposites," Journal of Applied Polymer Science, vol. 132, no. 23, Article ID 42073, 2015.

[30] L. Boge and E. Hjartfors, Surface Analysis of Polyethylene Pipes and Failure Characterization of Electrofusion Joints, Chalmers University of Technology, 2011.

[31] J. V. Gulmine, P. R. Janissek, H. M. Heise, and L. Akcelrud, "Polyethylene characterization by FTIR," Polymer Testing, vol. 21, no. 5, pp. 557-563, 2002.

[32] P. Pokharel, W. Jian, and S. Choi, "Evaluation of fatigue crack behavior in electron beam irradiated polyethylene pipes," Radiation Physics and Chemistry, vol. 126, pp. 103-110, 2016. 

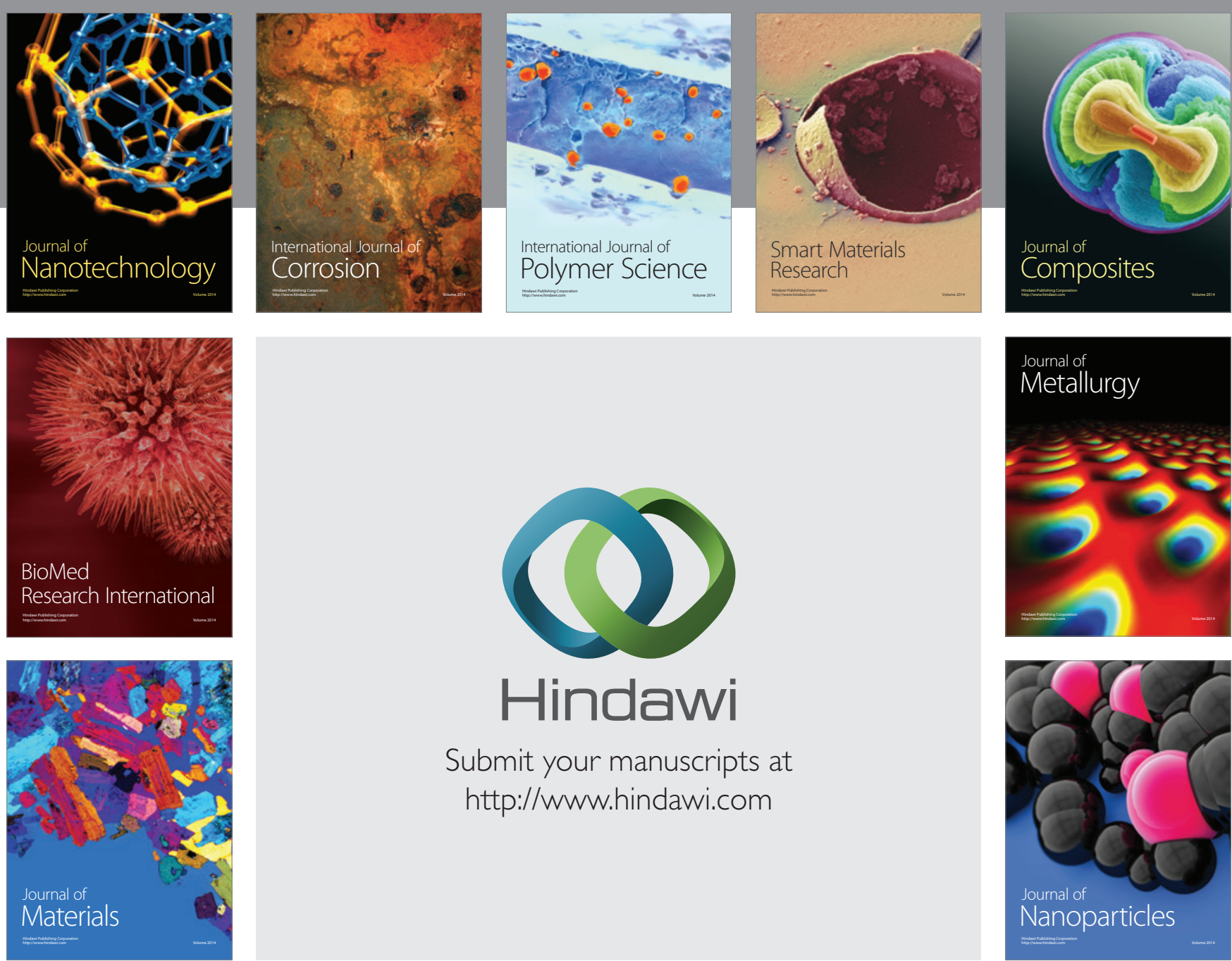

\section{Hindawi}

Submit your manuscripts at

http://www.hindawi.com

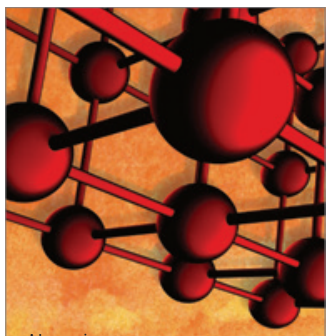

Materials Science and Engineering
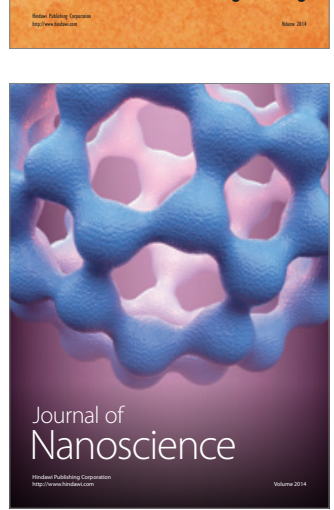
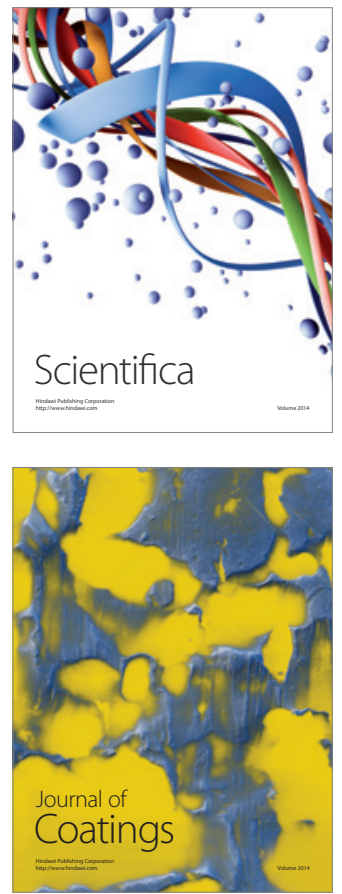
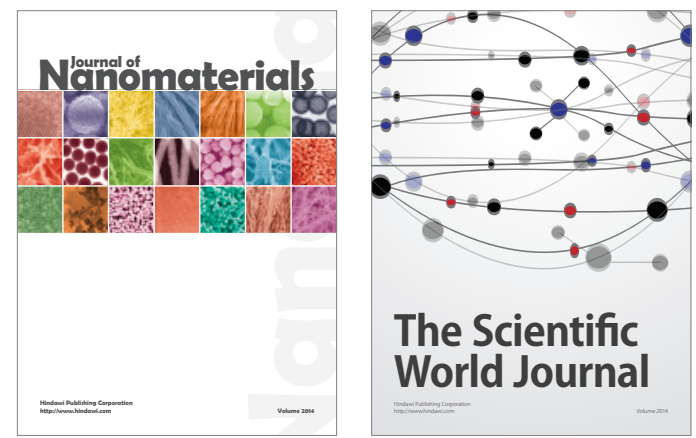

The Scientific World Journal
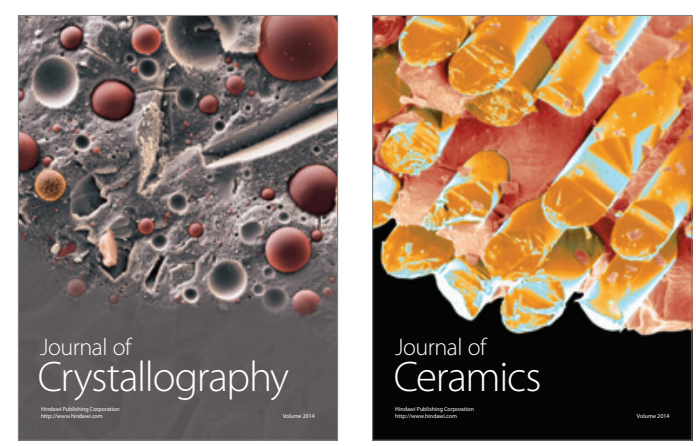
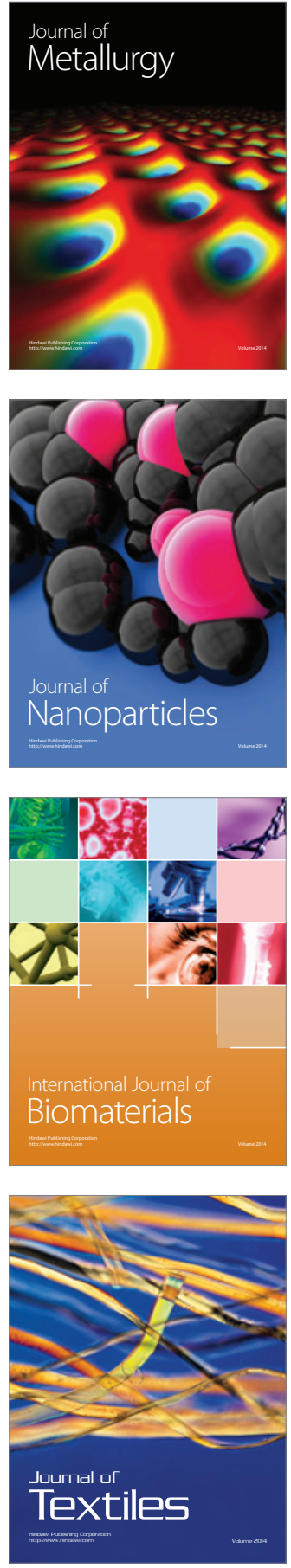